\title{
The association between skeletal maturation and adrenal androgen levels in obese children and adolescents
}

\author{
Sung Eun Kim, MD, \\ Joon Weon Jang, MD, \\ Moon Bae Ahn, MD, \\ Shin-Hee Kim, MD, \\ Won Kyoung Cho, MD, PhD \\ Kyoung Soon Cho, MD, \\ So Hyun Park, MD, PhD, \\ Min Ho Jung, MD, PhD, \\ Byoung Kyu Suh, MD, PhD
}

Department of Pediatrics, College of Medicine, The Catholic University of Korea, Seoul, Korea
Received: 12 September, 2016

Revised: 14 October, 2016

Accepted: 23 October, 2016

Address for correspondence:

Min Ho Jung, MD, PhD

Department of Pediatrics, Yeouido St. Mary's Hospital, College of Medicine, The Catholic University of Korea, 10 63(yuksam)-ro, Yeongdeungpo-gu, Seoul 07345, Korea

Tel: +82-2-3779-1131

Fax: +82-2-783-2589

E-mail:jmhpe@catholic.ac.kr

https://orcid.org/0000-0001-51887041
Purpose: This study aimed to investigate the association between skeletal maturation and adrenal androgen levels in obese children and adolescents. Methods: Fifty-three children and adolescents (aged 7-15 years) diagnosed as obese or overweight were investigated. Anthropometric measurements, bone age (BA) determination, serum biochemical analyses, and hormonal measurements were performed. The difference between BA and chronological age (BA-CA, dBACA) was calculated and used to represent the degree of advanced skeletal maturation. Results: Thirty-one subjects were classified into the obese group and 22 subjects into the overweight group. Insulin resistance as calculated by the homeostasis model assessment of insulin resistance (HOMA-IR) was significantly higher in the obese group than in the overweight group ( $4.03 \pm 2.20$ vs. $2.86 \pm 1.11, P=0.026)$. The skeletal maturation of the obese group was advanced, but the dBACA did not differ between the obese and overweight groups statistically (1.43 \pm 1.35 vs. $0.91 \pm 1.15$, $P=0.141$ ). Serum dehydroepiandrosterone sulfate (DHEA-S) levels were significantly higher in subjects with $d B A C A>1$ compared to those with $d B A C A \leq 1(104.3 \pm 62.2$ vs. $59.6 \pm 61.0, P=0.014)$. Correlation analyses demonstrated that $\mathrm{dBACA}$ was positively correlated with body mass index standard deviation scores $(r=0.35, P=0.010)$, fasting insulin $(r=0.36, P=0.009)$, HOMA-IR $(r=0.30, P=0.031)$, and insulin-like growth factorbinding protein-3 $(r=0.331, P=0.028)$. In multivariate linear regression analysis, HOMA-IR $(P=0.026)$ and serum DHEA-S $(P=0.032)$ were positively correlated with the degree of advanced skeletal maturation.

Conclusion: Advanced skeletal maturation is associated with increased insulin resistance and elevated DHEA-S levels in obese children and adolescents.

Keywords: Obesity, Androgens, Dehydroepiandrosterone sulfate, Child

\section{Introduction}

The prevalence of obesity in children and adolescents has been increasing worldwide and its development at an earlier age is reportedly associated with a greater risk of comorbidities and complications ${ }^{1,2}$. In particular, obesity during childhood is known to be linked to advanced pubertal development ${ }^{3,4}$. Moreover, several studies have found that obese children have bone ages (BAs) that exceed their chronological ages (CAs), which leads to relatively tall stature before puberty and during early puberty, though not to tall adult height ${ }^{5,6)}$.

Skeletal maturation is regulated by genetic, nutritional, and hormonal factors ${ }^{7)}$ and hormones including growth hormone, insulin-like growth factor (IGF), cortisol, estrogen, and androgens are known to influence the process ${ }^{7-9)}$. Children and adults with obesity demonstrate alterations in steroid hormone synthesis ${ }^{10,11}$ and studies have revealed the influence of steroid hormones on advanced skeletal maturation in obese children and 
adolescents. Increased levels of cortisol and testosterone have been observed in obese children ${ }^{10,12}$. However, the question as to which hormonal factors are most essential for stimulating skeletal maturation in this condition remains controversial ${ }^{7,13)}$.

Thus far, little information is available pertaining to the influence of adrenal androgens including dehydroepiandrosterone sulfate (DHEA-S) on advanced skeletal maturation. Therefore, the purpose of this study was to investigate the association between skeletal maturation and adrenal androgen levels in obese children and adolescents.

\section{Materials and methods}

\section{Subjects}

Fifty-three children and adolescents (age range, $7-15$ years; 32 male and 21 female patints) diagnosed as obese or overweight were investigated at the Department of Pediatrics, Yeouido St. Mary's Hospital between December 2014 and December 2015. Obesity was defined as body mass index (BMI) $\geq 95$ th percentile for age and sex according to the 2007 Korean National Growth Charts ${ }^{14)}$. Overweight status was defined as a BMI between the 85th and 94th percentile for age and sex.

Key exclusion criteria included chronic diseases (including cardiovascular, gastrointestinal, or respiratory disease), endocrine disorders requiring hormonal treatment, small for gestational age, idiopathic short stature, precocious puberty, premature adrenarche, and history of chronic drug use. Informed consent was given by all participants. Precocious puberty was defined by the onset of secondary sexual characteristics before the age of 8 years in girls and 9 years in boys ${ }^{15)}$. Premature adrenarche was defined as the appearance of sexual hair before the age of 8 years in girls and 9 years in boys. The study was reviewed and approved by the local Institutional Review Board.

\section{Anthropometric measurements}

Anthropometric measurements for the subjects included height, weight, and waist circumference (WC). Height was measured with a Harpenden's stadiometer. Weight and height were recorded to the nearest $0.1 \mathrm{~kg}$ and $0.1 \mathrm{~cm}$, respectively. BMI was calculated as $\mathrm{kg} / \mathrm{m}^{2}$. WC was measured halfway between the lowest rib and the superior border of the iliac crest at the end of expiration to the nearest $0.1 \mathrm{~cm}$. Waist-height ratio (WHR) was also calculated. The standard deviation scores (SDSs) for height, weight, and BMI were determined using the 2007 Korean National Growth Charts ${ }^{14)}$. Pubertal development (sexual maturity rating) was evaluated by the standards of Marshall and Tanner ${ }^{16}$. In males, sexual maturity rating was based on testicular enlargement and the development of pubic hair. In females, it was based on breast changes combined with the development of pubic hair. A testicular volume of $\geq 4 \mathrm{~mL}$ in males and stage 2-5 breast development in females were considered consistent with puberty. In defining pubertal stage, breast and gonadal stage were adopted preferentially if they were not corresponding with pubic hair stage.

\section{Laboratory evaluation and bone age determination}

Venous blood samples were taken after 10- to 12-hour overnight fasting. Serum concentrations of glucose, insulin, total cholesterol, triglyceride, low-density lipoprotein cholesterol (LDL-C), and high-density lipoprotein cholesterol (HDL-C) were analyzed. Hormonal measurements including cortisol, luteinizing hormone, follicle-stimulating hormone (FSH), estradiol, testosterone, and DHEA-S were performed. insulinlike growth factor-I (IGF-I) and IGF-binding protein-3 (IGFBP-3) were measured using an immunoradiometric assay. Dyslipidemia was defined as having one or more of the following abnormal lipid levels: total cholesterol $\geq 200 \mathrm{mg} /$ $\mathrm{dL}, \mathrm{LDL}-\mathrm{C} \geq 130 \mathrm{mg} / \mathrm{dL}, \mathrm{HDL}-\mathrm{C} \leq 35 \mathrm{mg} / \mathrm{dL}$, and triglycerides $\geq 150 \mathrm{mg} / \mathrm{dL}$ (based on the Third Report of the National Cholesterol Education Program ${ }^{17}$ and the American Diabetes Association $\left.{ }^{18}\right)$. The homeostasis model assessment of insulin resistance (HOMA-IR) was calculated using this equation: HOMA-IR $=$ fasting insulin $(\mu \mathrm{U} / \mathrm{mL}) \times$ fasting glucose $(\mathrm{mmol} /$ L) $/ 22.5^{19)}$.

BA was estimated from a radiograph of the left hand and wrist, using the Greulich and Pyle method ${ }^{20)}$. BA was read by a pediatric endocrinologist and a pediatric radiologist, and the mean of both readings was taken. Readers were permitted to read BAs as between two of the standard radiographs if they did not assume that either standard was an adequate match. If the difference of the readings was greater than 6 months, the readers discussed to determine the exact BA. The difference between the BA and CA (BA-CA, dBACA) was calculated and was used as a variable representing the degree of advanced skeletal maturation. $\mathrm{dBACA}>1$ was considered significantly advanced skeletal maturation.

\section{Statistical analysis}

Values of measured parameters are expressed as mean \pm standard deviation. Statistical analyses were performed using SPSS ver. 18 (SPSS Inc., Chicago, IL, USA). Continuous variables were compared by $t$-test or Mann-Whitney $U$-test, as appropriate. Differences in proportions were tested using Fisher exact test. Pearson correlation coefficients were calculated to examine the relationship of the BMI SDS and BBACA to anthropometric and biochemical variables. For the variables that did not show normal distribution, correlations were evaluated with Spearman rank-order correlation coefficients. Multivariate linear regression analyses were conducted for the dependent variable, dBACA (degree of advanced skeletal maturation), including CA, the state of obesity, the state of puberty, and HOMA-IR as independent variables. $P<0.05$ were considered statistically significant. 


\section{Results}

\section{Clinical and laboratory characteristics of the subjects}

Thirty-one subjects were classified into the obese group and 22 subjects were classified into the overweight group (Table 1). Of the subjects, 32 (60.4\%) were prepubertal, and $21(39.6 \%)$ were in puberty $(10$ subjects in Tanner stage 2,11 subjects in Tanner stage 3). The majority of subjects showed pubic hair Tanner stage 1 . The number of overweight subjects with pubic hair Tanner stage 1, stage 2-3, and stage 4-5 was 28, 2, and 1 , respectively. The number of obese subjects with pubic hair Tanner stage 1 , stage $2-3$, and stage $4-5$ was 21,1 , and 0 , respectively. The CA of the obese group was younger compared to the overweight group, whereas the BA of the obese group was not different from that of the overweight group. The obese group had significantly higher WHR $(0.59 \pm 0.05$ vs. $0.54 \pm 0.04$, $P<0.001)$, BMI $\left(25.4+3.4 \mathrm{~kg} / \mathrm{m}^{2}\right.$ vs. $\left.22.5 \pm 2.0 \mathrm{~kg} / \mathrm{m}^{2}, P<0.001\right)$, and BMI SDS $(2.19 \pm 0.45$ vs. $1.32 \pm 0.19, P<0.001)$ compared with those of the overweight group. HOMA-IR was significantly higher in the obese group compared to the overweight group ( $4.03 \pm 2.20$ vs. $2.86 \pm 1.11, P=0.026)$. The skeletal maturation of the obese group was advanced, but the dBACA did not differ between the obese and overweight groups statistically $(1.43 \pm 1.35$ vs. $0.91 \pm 1.15, P=0.141)$.

\section{DHEA-S levels}

Among the total subjects, serum DHEA-S levels were significantly lower in the obese group than in the overweight group $(70.8 \pm 56.7 \mu \mathrm{g} / \mathrm{dL}$ vs. $109.4 \pm 70.0 \mu \mathrm{g} / \mathrm{dL}, P=0.033$ ) (Table $2)$. Serum DHEA-S levels were significantly lower in obese males than in overweight males $(95.9 \pm 61.2 \mu \mathrm{g} / \mathrm{dL}$ vs. $146.9 \pm 58.5$

Table 1. Characteristics of the obese and overweight subjects

\begin{tabular}{lccc}
\hline Characteristic & Obese $(n=31)$ & Overweight $(n=22)$ & $P$-value \\
\hline Male sex & $18(58.1)$ & $14(63.6)$ & 0.902 \\
In puberty & $11(35.5)$ & $10(45.5)$ & 0.655 \\
CA (yr) & $9.3 \pm 1.9$ & $10.6 \pm 1.8$ & 0.013 \\
WHR & $0.59 \pm 0.04$ & $0.54 \pm 0.04$ & $<0.001$ \\
BMI $\left(\mathrm{kg} / \mathrm{m}^{2}\right)$ & $25.4 \pm 3.4$ & $22.5 \pm 2.0$ & $<0.001$ \\
BMI SDS & $2.19 \pm 0.45$ & $1.32 \pm 0.19$ & $<0.001$ \\
SBP $(\mathrm{mmHg})$ & $114.5 \pm 19.8$ & $112.1 \pm 13.0$ & 0.622 \\
DBP $(\mathrm{mmHg})$ & $76.8 \pm 23.0$ & $69.3 \pm 13.3$ & 0.177 \\
BA (yr) & $10.5 \pm 2.5$ & $11.5 \pm 2.3$ & 0.240 \\
dBACA & $1.43 \pm 1.35$ & $0.91 \pm 1.15$ & 0.141 \\
HOMA-IR & $4.03 \pm 2.20$ & $2.86 \pm 1.11$ & 0.026 \\
dBACA $\geq 1$ & $21(67.7)$ & $12(54.5)$ & 0.395 \\
Dyslipidemia & $10(32.3)$ & $7(31.8)$ & 1.000 \\
\hline Val &
\end{tabular}

Values are presented as number (\%) or mean \pm standard deviation. CA, chronological age; WHR, waist-height ratio; BMI, body mass index; SDS, standard deviation score; SBP, systolic blood pressure; DBP, diastolic blood pressure; BA, bone age; dBACA, difference between bone age and chronological age; HOMA-IR, homeostasis model assessment of insulin resistance. $\mu \mathrm{g} / \mathrm{dL}, P=0.025$ ) (Table 2). However, the serum DHEA-S levels of obese females did not differ from those of overweight females $(37.9 \pm 26.7 \mu \mathrm{g} / \mathrm{dL}$ vs. $43.8 \pm 25.3 \mu \mathrm{g} / \mathrm{dL}, P=0.625)$. Serum DHEA-S levels were similar between prepubertal males and pubertal males $(106.8 \pm 61.2 \mu \mathrm{g} / \mathrm{dL}$ vs. $160.4 \pm 61.6 \mu \mathrm{g} / \mathrm{dL}$, $P=0.051$ ), as well as between prepubertal females and pubertal females $(26.6 \pm 17.3 \mu \mathrm{g} / \mathrm{dL}$ vs. $46.9 \pm 27.0 \mu \mathrm{g} / \mathrm{dL}, P=0.087$ ) (Table 3). Serum DHEA-S levels were significantly higher in subjects with $\mathrm{dBACA}>1$ compared to those of subjects with $\mathrm{dBACA} \leq 1$ $(104.3 \pm 62.2 \mu \mathrm{g} / \mathrm{dL}$ vs. $59.6 \pm 61.0 \mu \mathrm{g} / \mathrm{dL}, P=0.014)$ (Fig. 1).

\section{Correlation analyses and multiple linear regression analysis of factors related to advanced skeletal maturation}

Correlation analyses revealed that BMI SDS was positively correlated with WHR $(r=0.70, P<0.001)$ and dBACA $(r=0.35, P=$ $0.010)$ (Table 4). Additionally, dBACA was positively correlated with DHEA-S $(r=0.32, P=0.019)$, fasting insulin $(r=0.34$, $P=0.015)$, and HOMA-IR $(r=0.35, P=0.012)$. Sex steroids (estradiol and testosterone) did not show significant correlation with BMI SDS or ABACA (data not shown).

In order to investigate the influence of clinical and bioche-

Table 2. Hormonal profiles of the obese and overweight subjects

\begin{tabular}{lccc}
\hline Variable & Obese $(\mathrm{n}=31)$ & Overweight $(\mathrm{n}=22)$ & $P$-value \\
\hline Male sex & $18(58.1)$ & $14(63.6)$ & 0.902 \\
Estradiol $(\mathrm{pg} / \mathrm{mL})$ & & & \\
Total & $1.32 \pm 1.77$ & $1.70 \pm 1.81$ & 0.459 \\
Male & $1.57 \pm 2.35$ & $1.78 \pm 1.98$ & 0.798 \\
Female & $1.21 \pm 0.98$ & $1.56 \pm 1.59$ & 0.210 \\
Testosterone $(\mathrm{ng} / \mathrm{mL})$ & & & \\
Total & $1.12 \pm 3.64$ & $0.27 \pm 0.40$ & 0.290 \\
Male & $1.80 \pm 4.62$ & $0.37 \pm 0.47$ & 0.257 \\
Female & $0.10 \pm 0.06$ & $0.07 \pm 0.02$ & 0.220 \\
Insulin $(\mu \mathrm{U} / \mathrm{mL})$ & $16.3 \pm 8.6$ & $11.8 \pm 4.3$ & 0.028 \\
IGF-I $(\mathrm{ng} / \mathrm{mL})$ & $268.2 \pm 128.0$ & $339.6 \pm 173.3$ & 0.115 \\
IGFBP-3 $(\mathrm{ng} / \mathrm{mL})$ & $2,456.5 \pm 631.9$ & $2,429.5 \pm 423.7$ & 0.873 \\
DHEA-S $(\mu \mathrm{g} / \mathrm{dL})$ & & & \\
Total & $70.8 \pm 56.7$ & $109.4 \pm 70.0$ & 0.033 \\
Male & $95.9 \pm 61.2$ & $146.9 \pm 58.5$ & 0.025 \\
Female & $37.9 \pm 26.7$ & $43.8 \pm 25.3$ & 0.625 \\
\hline Values & &
\end{tabular}

Values are presented as number (\%) or mean \pm standard deviation. IGF-I, insulin-like growth factor-I; IGFBP-3, insulin-like growth factor-binding protein-3; DHEA-S, dehydroepiandrosterone sulfate.

Table 3. Comparison of dehydroepiandrosterone sulfate (DHEA-S) by pubertal status

\begin{tabular}{lccc}
\hline Variable & Prepubertal $(n=32)$ & Pubertal $(n=21)$ & $P$-value \\
\hline Male sex & $25(78.1)$ & $7(33.3)$ & 0.003 \\
DHEA-S $(\mu \mathrm{g} / \mathrm{dL})$ & & & \\
$\quad$ Total & $88.7 \pm 64.0$ & $84.8 \pm 67.9$ & 0.832 \\
Male & $106.8 \pm 61.2$ & $160.4 \pm 61.6$ & 0.051 \\
Female & $26.6 \pm 17.3$ & $46.9 \pm 27.0$ & 0.087 \\
\hline
\end{tabular}

Values are presented as number (\%) or mean \pm standard deviation. 


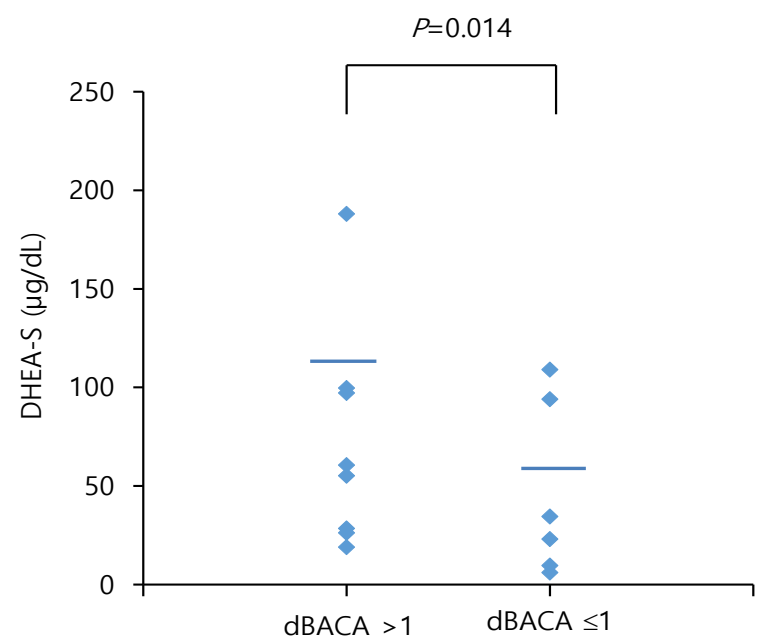

Fig. 1. Serum dehydroepiandrosterone sulfate (DHEA-S) levels were significantly higher in subjects with the difference between the bone age and chronological age $(\mathrm{dBACA})>1$ compared to those of subjects with $\mathrm{dBACA} \leq 1$

Table 4. Relationships of the BMI SDS and ABACA to clinical and biochemical parameters by correlation analyses

\begin{tabular}{lccccc}
\hline \multirow{2}{*}{ Variable } & \multicolumn{2}{c}{ BMI SDS } & & \multicolumn{2}{c}{ dBACA } \\
\cline { 2 - 3 } \cline { 5 - 6 } & \multicolumn{1}{c}{} & $P$-value & & $r$ & $P$-value \\
\hline WHR & 0.70 & $<0.001$ & & 0.21 & 0.135 \\
dBACA & 0.35 & 0.010 & & - & - \\
DHEA-S & -0.19 & 0.183 & & 0.32 & 0.019 \\
Fasting insulin & 0.27 & 0.062 & & 0.34 & 0.015 \\
HOMA-IR & 0.28 & 0.050 & & 0.35 & 0.012 \\
\hline
\end{tabular}

BMI, body mass index; SDS, standard deviation score; dBACA, difference between bone age and chronological age; WHR, waist-height ratio; DHEA-S, dehydroepiandrosterone sulfate; HOMA-IR, homeostasis model assessment of insulin resistance.

mical variables on the degree of advanced skeletal maturation, a multiple linear regression analysis was performed (Table 5). This analysis revealed that HOMA-IR $(P=0.026)$ and serum DHEA-S $(P=0.032)$ were both positively correlated with the degree of advanced skeletal maturation (dBACA). In this model, CA, obesity (in comparison to overweight status), and puberty (in comparison to the prepubertal state) were not associated with advanced skeletal maturation. Sex steroids and IGF-I, IGFBP-3 and BMI SDS were not associated with advanced skeletal maturation in multivariate regression analyses.

\section{Discussion}

This study demonstrated that advanced skeletal maturation in obese and overweight children is associated with elevated HOMA-IR and DHEA-S levels. Therefore, it can be postulated that skeletal maturation in childhood obesity is directly affected by metabolic alterations such as insulin resistance and shifts in hormones, including adrenal androgens.

Previous studies have shown that obese children have BAs that exceed their CAs, which results in a relatively tall stature
Table 5. Final significant outcomes of multivariate linear regression models examining the influence of clinical and biochemical variables on the degree of advanced skeletal maturation ( $\mathrm{dBACA})$ in obese and overweight subjects

\begin{tabular}{lccc}
\hline Variable & Coefficient & SE & $P$-value \\
\hline CA & -0.111 & 0.116 & 0.345 \\
Obesity & 0.191 & 0.422 & 0.653 \\
Puberty & -0.144 & 0.364 & 0.695 \\
HOMA-IR & 0.258 & 0.386 & 0.026 \\
DHEA-S & 0.007 & 0.354 & 0.032 \\
\hline
\end{tabular}

dBACA, difference between bone age and chronological age; CA, chronological age; DHEA-S, dehydroepiandrosterone sulfate; HOMA-IR, homeostasis model assessment of insulin resistance; $\mathrm{SE}$, standard error.

during the prepubertal and early pubertal stages, though not to tall adult height ${ }^{2,9,21)}$. The degree of obesity has been shown to be significantly correlated to the advancement of skeletal maturation in both univariate and multivariate regression analyses including sex, age, and pubertal status as independent variables ${ }^{7,21}$. In the present study, two-thirds of obese children and adolescents demonstrated significantly advanced skeletal maturation $(\mathrm{dBACA}>1)$. BMI SDS correlated significantly to $\mathrm{dBACA}$ in the univariate analysis, whereas a significant correlation was not demonstrated in the multivariate analysis. A possible explanation for the inconsistent findings of our study is that the number of subjects with very high BMI SDSs who were included was not enough to reveal the correlation. Alternatively, it may demonstrate that skeletal maturation is influenced significantly not by the degree of obesity itself, but by other factors related to obesity.

Hormones that are considered to be associated with accelerated skeletal maturation in obese subjects include estrogen, testosterone, IGF-I, and adrenal androgens. Average 24-hour estradiol levels measured by an ultrasensitive recombinant cell bioassay have been reported to correlate with skeletal maturation" ${ }^{9)}$. Meanwhile, there have been controversies regarding testosterone concentrations in obese children and adolescents. One study reported decreased testosterone concentrations in obese prepubertal boys and girls ${ }^{22}$. Other studies reported similar testosterone levels in both obese and normal-weight prepubertal boys and girls ${ }^{23)}$, whereas studies in obese pubertal females revealed higher testosterone levels compared to those of lean pubertal females ${ }^{24}$. Recently, a noteworthy study described the contribution of IGF-I to the acceleration of skeletal maturation in obese children ${ }^{7}$. The study demonstrated that IGF-I concentration was significantly related to the acceleration of skeletal maturation independent of pubertal status and sex. It has been reported that not only is the IGF-I produced by liver responsible for growth, but also IGF-I produced by different tissues ${ }^{25,26)}$, including adipose tissue ${ }^{27,28)}$. In the previous studies, increased IGF-I levels were associated with accelerated $\mathrm{BA}^{29,30)}$, while the IGF-I deficiency syndrome was characterized by a delay in skeletal maturation ${ }^{31}$. Therefore, it could be postulated that the increased production of IGF-I 
by adipose tissue in obese subjects lead to the acceleration of skeletal maturation. In our study, IGF-I was not correlated to advanced skeletal maturation, while IGFBP-3 was significantly positively correlated to advanced skeletal maturation in univariate analyses. Further studies are needed to investigate the influence of the IGF system on changes in skeletal maturation in obesity.

The most important finding of the present study is that the adrenal androgen DHEA-S was positively correlated with advanced skeletal maturation in obese or overweight children who were prepubertal and in early puberty. Previous studies have shown that obese children tend to have increased DHEA-S levels ${ }^{12,32)}$. Furthermore, DHEA-S, as well as testosterone, was hypothesized to stimulate skeletal maturation and growth via a direct growth hormone-independent effect on the growth plate ${ }^{33,34)}$.

Plasma levels of adrenal androgens, particularly those of the $\Delta^{5}$ pathway (DHEA and DHEA-S) are the best indicator of the development of the zona reticularis in the adrenal $\operatorname{cortex}^{35}$. It was reported that adrenal androgen DHEA-S possesses particular characteristics that differ from the other steroid hormones in obese children. According to the study by Reinehr et al. ${ }^{36)}$, prepubertal obese children showed significantly higher androgens, mineralocorticoid precursors, and glucocorticoids compared with normal-weight children. After weight loss, most of the hormones decreased significantly, but DHEA-S remained elevated. These findings support the presence of a premature, increased, and irreversible maturation of the zona reticularis in the prepubertal obese children. It has not been clarified whether obesity is the initial event, with only secondarily developed premature adrenarche, or whether premature adrenarche is occurs first and causes the development of obesity as a secondary process ${ }^{23,37)}$.

Several mechanisms that explain the increased production of adrenal androgens, DHEA-S, and androstenedione in obesity have been suggested. Firstly, leptin was shown to enhance the formation of adrenal androgens in a dose-dependent manner by stimulating 17,20 -lyase activity ${ }^{38)}$. Therefore, it can be hypothesized that increased adrenal androgen levels in obese children are due to the enhanced secretion of leptin by adipose tissue $^{36)}$. Secondly, increased $3 \beta$-hydroxysteroid dehydrogenase expression via an insulin receptor substrate 1 - and 2-dependent pathway can enhance the $\Delta^{5}$ to $\Delta^{4}$ conversion of DHEA-S to androstenedione ${ }^{39)}$. Therefore, elevated insulin levels in obese children and adolescents may activate this enzyme in the adrenal gland and in the peripher $y^{36)}$. Based on previous studies, our finding that advanced skeletal maturation in obese and overweight children is associated with increased HOMAIR is of considerable significance. In other words, insulin resistance may be the functional link between accelerated skeletal maturation and increased adrenal androgens in obese children. A recent study suggested that irisin, a newly discovered myokine affecting metabolic and glucose homeostasis, is related to pubertal development and insulin resistance in obese children $^{40}$. Therefore, further studies need to concentrate on the effects of various hormones and cytokines on the growth plate of obese children and adolescents.

This study has some limitations. Firstly, to validate the significance of the findings of the present study, controls with normal BMI would have to be enrolled. The overweight and obese group may share variables to some extent and have overlapped biochemical or anthropometric changes. Secondly, the sample size was small and the distribution of sex and pubertal status of the groups was not exactly equivalent, although the difference was not significant statistically. Moreover, the CA of the obese group was significantly younger compared to the overweight group. This factor may have biased the results of the study. Thirdly, the number of subjects with a very high BMI SDS was not sufficient, so the effect of adiposity might be estimated to be less significant. Additionally, due to the cross-sectional study design, the longitudinal features of skeletal maturation, obesity, and adrenal androgens were unable to be investigated. In spite of these limitations, results of the multivariate regression analysis could supply some evidence for the role of insulin and DHEA-S on changes in skeletal maturation in obese children and adolescents. There is a great need for further investigations as to the influence of advanced skeletal maturation on precocious pubertal development and growth after puberty. In the further study, the influences and interactions of insulin and leptin on the changes of skeletal maturation in obese children need to be investigated systematically, because increased levels of these hormones and resistance to these hormones are known to be involved in the pathophysiologic mechanism of obesity.

In conclusion, advanced skeletal maturation is associated with increased insulin resistance and DHEA-S levels in obese children and adolescents. Future studies of obese and overweight children are required to investigate the mechanisms of elevated adrenal androgens and the consequences of increased insulin (or insulin resistance) on skeletal maturation.

\section{Conflict of interest}

No potential conflict of interest relevant to this article was reported.

\section{References}

1. Daniels SR. Complications of obesity in children and adolescents. Int J Obes (Lond) 2009;33 Suppl 1:S60-5.

2. Wabitsch M. Overweight and obesity in European children: definition and diagnostic procedures, risk factors and consequences for later health outcome. Eur J Pediatr 2000;159 Suppl 1:S8-13.

3. Aksglaede L, Juul A, Olsen LW, Sørensen TI. Age at puberty and the emerging obesity epidemic. PLoS One 2009; 4:e8450.

4. Denzer C, Weibel A, Muche R, Karges B, Sorgo W, Wabitsch M. Pubertal development in obese children and adolescents. Int J Obes (Lond) 2007;31:1509-19. 
5. Kleber M, Schwarz A, Reinehr T. Obesity in children and adolescents: relationship to growth, pubarche, menarche, and voice break. J Pediatr Endocrinol Metab 2011;24:12530 .

6. Johnson W, Stovitz SD, Choh AC, Czerwinski SA, Towne B, Demerath EW. Patterns of linear growth and skeletal maturation from birth to 18 years of age in overweight young adults. Int J Obes (Lond) 2012;36:535-41.

7. Reinehr T, de Sousa G, Wabitsch M. Relationships of IGF-I and andrrogens to skeletal maturation in obese children and adolescents. J Pediatr Endocrinol Metab 2006;19:113340.

8. Phillip M, Moran O, Lazar L. Growth without growth hormone. J Pediatr Endocrinol Metab 2002;15 Suppl 5:1267-72

9. Klein KO, Larmore KA, de Lancey E, Brown JM, Considine RV, Hassink SG. Effect of obesity on estradiol level, and its relationship to leptin, bone maturation, and bone mineral density in children. J Clin Endocrinol Metab 1998;83:346975.

10. Reinehr T, Andler W. Cortisol and its relation to insulin resistance before and after weight loss in obese children. Horm Res 2004;62:107-12.

11. Björntorp P, Rosmond R. Neuroendocrine abnormalities in visceral obesity. Int J Obes Relat Metab Disord 2000;24 Suppl 2:S80-5.

12. Reinehr T, de Sousa G, Roth CL, Andler W. Androgens before and after weight loss in obese children. J Clin Endocrinol Metab 2005;90:5588-95.

13. Sopher AB, Jean AM, Zwany SK, Winston DM, Pomeranz $\mathrm{CB}$, Bell JJ, et al. Bone age advancement in prepubertal children with obesity and premature adrenarche: possible potentiating factors. Obesity (Silver Spring) 2011;19:125964.

14. Moon JS, Lee SY, Nam CM, Choi JM, Choe BK, Seo JW, et al. 2007 Korean National Growth Charts: review of developmental process and an outlook. Korean J Pediatr 2008;51:1-25.

15. Garibaldi LR, Chemaitilly W. Disorders of pubertal development. In: Kliegman RM, Stanton B, St. Geme J, Schor N, Behrman RE. Nelson textbook of pediatrics. 20th ed. Philadelphia: Elsevier Saunders, 2016:2656-62.

16. Marshall WA, Tanner JM. Variations in pattern of pubertal changes in girls. Arch Dis Child 1969;44:291-303.

17. Expert Panel on Detection, Evaluation, and Treatment of High Blood Cholesterol in Adults. Executive Summary of The Third Report of The National Cholesterol Education Program (NCEP) Expert Panel on Detection, Evaluation, And Treatment of High Blood Cholesterol In Adults (Adult Treatment Panel III). JAMA 2001;285:2486-97.

18. American Diabetes Association. Management of dyslipidemia in children and adolescents with diabetes. Diabetes Care 2003;26:2194-7.

19. Valerio G, Licenziati MR, Iannuzzi A, Franzese A, Siani P, Riccardi G, et al. Insulin resistance and impaired glucose tolerance in obese children and adolescents from Southern Italy. Nutr Metab Cardiovasc Dis 2006;16:279-84.

20. Greulich WW, Pyle SI. Radiographic atlas of skeletal development of the hand and wrist. Stanford: Stanford University Press, 1959.

21. Russell DL, Keil MF, Bonat SH, Uwaifo GI, Nicholson JC, McDuffie JR, et al. The relation between skeletal maturation and adiposity in African American and Caucasian children. J Pediatr 2001;139:844-8.

22. Gascón F, Valle M, Martos R, Ruz FJ, Ríos R, Montilla $\mathrm{P}$, et al. Sex hormone-binding globulin as a marker for hyperinsulinemia and/or insulin resistance in obese children. Eur J Endocrinol 2000;143:85-9.

23. Pintor C, Loche S, Faedda A, Fanni V, Nurchi AM, Corda R. Adrenal androgens in obese boys before and after weight loss. Horm Metab Res 1984;16:544-8.

24. Silfen ME, Denburg MR, Manibo AM, Lobo RA, Jaffe R, Ferin M, et al. Early endocrine, metabolic, and sonographic characteristics of polycystic ovary syndrome (PCOS): comparison between nonobese and obese adolescents. J Clin Endocrinol Metab 2003;88:4682-8.

25. Schlechter NL, Russell SM, Spencer EM, Nicoll CS. Evidence suggesting that the direct growth-promoting effect of growth hormone on cartilage in vivo is mediated by local production of somatomedin. Proc Natl Acad Sci U S A 1986;83:7932-4.

26. Sjögren K, Liu JL, Blad K, Skrtic S, Vidal O, Wallenius V, et al. Liver-derived insulin-like growth factor I (IGF-I) is the principal source of IGF-I in blood but is not required for postnatal body growth in mice. Proc Natl Acad Sci U S A 1999;96:7088-92.

27. Wabitsch M, Blum WF, Muche R, Heinze E, Haug C, Mayer $\mathrm{H}$, et al. Insulin-like growth factors and their binding proteins before and after weight loss and their associations with hormonal and metabolic parameters in obese adolescent girls. Int J Obes Relat Metab Disord 1996;20:1073-80.

28. Wabitsch M, Hauner H, Heinze E, Teller WM. The role of growth hormone/insulin-like growth factors in adipocyte differentiation. Metabolism 1995;44(10 Suppl 4):45-9.

29. Harris DA, Van Vliet G, Egli CA, Grumbach MM, Kaplan SL, Styne DM, et al. Somatomedin-C in normal puberty and in true precocious puberty before and after treatment with a potent luteinizing hormone-releasing hormone agonist. J Clin Endocrinol Metab 1985;61:152-9.

30. Grumbach MM, Styne MD. Puberty: ontogeny, neuroendocrinology, physiology, and its disorders. In: Larsen PR, Kronenberg HM, Melmed S, Polonsky KS, editors. Williams textbook of endocrinology. 10th ed. Philadelphia: Saunders, 2003;1115-286.

31. Savage MO, Blum WF, Ranke MB, Postel-Vinay MC, Cotterill AM, Hall K, et al. Clinical features and endocrine status in patients with growth hormone insensitivity (Laron syndrome). J Clin Endocrinol Metab 1993;77:1465-71.

32. Remer T, Manz F. Role of nutritional status in the regulation 
of adrenarche. J Clin Endocrinol Metab 1999;84:3936-44.

33. l'Allemand D, Schmidt S, Rousson V, Brabant G, Gasser T, Grüters A. Associations between body mass, leptin, IGF-I and circulating adrenal androgens in children with obesity and premature adrenarche. Eur J Endocrinol 2002;146:53743.

34 Garn SM, Clark DC. Nutrition, growth, development, and maturation: findings from the ten-state nutrition survey of 1968-1970. Pediatrics 1975;56:306-19.

35. Forest MG, de Peretti E, Bertrand J. Age-related response of plasma 4-and 5-androgens, their precursors and cortisol to ACTH, from infancy to puberty. In: Cacciari E, Prader A, editors. Pathophysiology of puberty. London: Academic Press, 1980;137-55.

36. Reinehr T, Kulle A, Wolters B, Lass N, Welzel M, Riepe F, et al. Steroid hormone profiles in prepubertal obese children before and after weight loss. J Clin Endocrinol Metab
2013;98:E1022-30.

37. Saenger P, Dimartino-Nardi J. Premature adrenarche. J Endocrinol Invest 2001;24:724-33.

38. Biason-Lauber A, Zachmann M, Schoenle EJ. Effect of leptin on CYP17 enzymatic activities in human adrenal cells: new insight in the onset of adrenarche. Endocrinology 2000;141:1446-54.

39. Gingras S, Côté S, Simard J. Multiple signal transduction pathways mediate interleukin-4-induced 3betahydroxysteroid dehydrogenase/Delta5-Delta4 isomerase in normal and tumoral target tissues. J Steroid Biochem Mol Biol 2001;76:213-25.

40. Reinehr T, Elfers C, Lass N, Roth CL. Irisin and its relation to insulin resistance and puberty in obese children: a longitudinal analysis. J Clin Endocrinol Metab 2015;100:2123-30. 